\title{
THE EFFECTIVENESS OF \\ FOOD SAFETY \& WORKPLACE INTERVENTIONS FOR FOOD HANDLERS
}

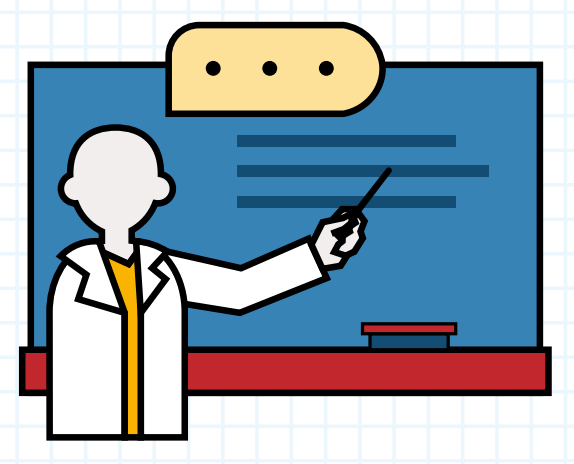

Researchers conducted a systematic review of the effectiveness of training and education interventions to improve food safety in restaurants and food service settings.

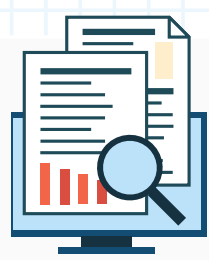

SYSTEMATIC REVIEWS are a structured and transparent method to summarize the results of all available research studies on a topic.

\section{How this systematic review worked}

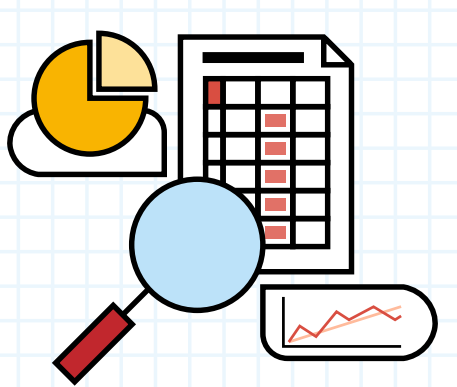

The researchers evaluated 18 randomized controlled trials (RCTs) and 29 non-randomized controlled trials that investigated different types of training and education interventions.

\section{RANDOMIZED CONTROL TRIALS}

An experimental study that randomly assigns subjects to two groups: one group receives the intervention that's being assessed while the other group receives no intervention.

\section{NON-RANDOMIZED CONTROL TRIALS}

$\uparrow$ An experimental study in which people are allocated to different intervention groups using methods that are not random.

\section{What they found}

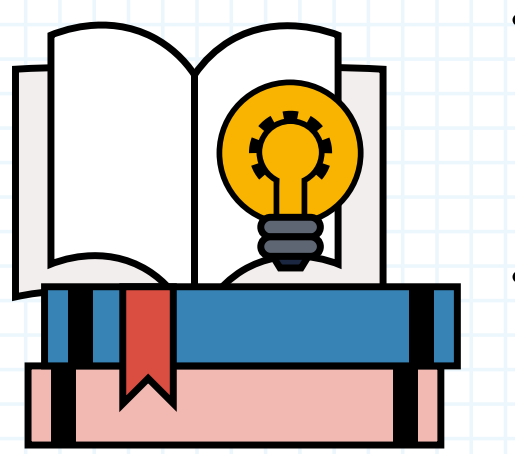

- Among RCT studies, high confidence was found that training and education interventions are effective to improve food handler knowledge about food safety.

- There was no consistent effect of these interventions to improve food handler attitudes and behaviours, or food premise inspection scores.

- Non-randomized studies found a positive effect of training and education interventions on all outcomes, but these studies are less reliable because they are more susceptible to biases.

- Risks of bias were found among two-thirds of RCT study outcomes and in nearly all non-randomized study outcomes.

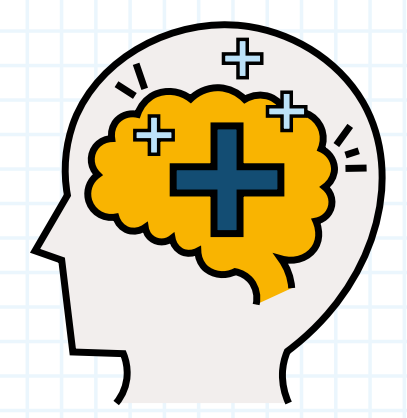

\section{Conclusion}

The study results support the importance of training and certification programs to improve food handler knowledge of food safety, but more research is needed to identify effective strategies to achieve behaviour change in this population.

\section{For more information}

Read the full article online by scanning the QR code below.

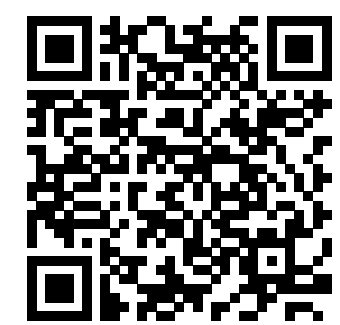

Young, I., Greig, J., Wilhelm, B.J., \& Waddell, L.A. (2019). Effectiveness of food handler training and education interventions: a systematic review and meta-analysis. Journal of Food Protection 82(10), 1714-1728.

Prepared by Christine Lum and lan Young, 2020. 